\title{
The Development of Lateralization Abilities in Children with Bilateral Cochlear Implants
}

\author{
Heike Kühn $^{a}$ Franz Schön ${ }^{a}$ Karola Edelmann ${ }^{b}$ Stefan Brill ${ }^{a}$ \\ Joachim Müllerc \\ ${ }^{a}$ Department of Otolaryngology, University of Würzburg, Würzburg, bVivantes Clinic, Berlin, and \\ 'ENT Clinic, Ludwig-Maximilians-Universität, Munich, Germany
}

\section{Key Words}

Bilateral cochlear implant · Localization · Lateralization · Children · MED-EL cochlear implant

\begin{abstract}
Objectives: The purpose of this study was to investigate the development of lateralization skills in children who received bilateral cochlear implants (CIs) in sequential operations. Methods: The lateralization skills of 9 children with a mean age of 4.1 years at the first surgery and 5.5 years at the second surgery were assessed at 3 time intervals. Children were assessed with a 3-loudspeaker setup (front, left and right) at 0.9 years (interval I) and 1.6 years (interval II) after the second implantation, and after 5.3 years of bilateral implant use (interval III) with a 9-loudspeaker setup in the frontal horizontal plane between $-90^{\circ}$ and $90^{\circ}$ azimuth. Results: With bilateral implants, a significant decrease in lateralization error was noted between test interval I $\left(45.0^{\circ}\right)$ and II $\left(23.3^{\circ}\right)$, with a subsequent significant decrease at test interval III $\left(4.7^{\circ}\right)$. Unilateral performance with the CI did not improve significantly between the first 2 intervals; however, there was a bias of responses towards the unilateral side by test interval III. Conclusions: The lateralization abilities of children with bilateral CIs develop in a relatively short period of time (1-2 years) after the second implant. Children appear to be able to acquire binaural skills after bilateral cochlear implantation.

Copyright $\odot 2013$ S. Karger AG, Basel
\end{abstract}

\section{Introduction}

Bilateral cochlear implantation is becoming an increasingly popular method of restoring binaural listening abilities in adults. The benefit of binaural hearing is significant, including understanding speech in background noise or reverberant environments, and spatial hearing. 
Binaural hearing underpins such skills by giving the listener access to time, level and spectral differences between signals.

Data in adults show clear benefits from bilateral cochlear implantation with regard to both speech perception and sound lateralization [1-8] and that significant improvements in localization occur upon bilateral cochlear implant (CI) use, in comparison to unilateral listening conditions [9-12]. Furthermore, Schleich et al. [13] found that late deafened adult bilateral CI users benefit from the same effects as normal-hearing subjects, namely the squelch effect, head shadow effect and binaural summation effect. In contrast, Grantham et al. [14] demonstrated that most users with unilateral implants are unable to localize above chance using differential head shadowing.

Experience has shown that hearing-impaired children, including those prelingually deafened, are also able to take advantage of these bilateral listening skills. Litovsky [15] investigated changes in the ability to detect minimal angular shifts of sound sources in precedence conditions in normal-hearing children at 2 time intervals. A significant increase in performance between the 2 intervals ( 8 months and 5 years of age) was found, which indicates the development of binaural processing skills at an early stage in normal-hearing children. A report by Kühn-Inacker et al. [16] indicated that bilateral CIs promote improvements in communicative behavior and in speech perception in noise. Children scored significantly better on speech-in-quiet and speech-in-noise tests in the bilateral condition when compared to their best unilateral condition. Observation of the therapy session also showed that reduced listening effort was required, with the children reported as being more relaxed and at ease. These benefits were also shown on objective measures; early bilateral cochlear implantation showed preservation of the central auditory system, as demonstrated on P1 measurements [17]. The authors, Bauer et al. [17], suggested that this was related to the high degree of plasticity of the system, which allowed potential development of these binaural skills. A number of recent studies have confirmed and elaborated on children's potential to use bilateral CIs to achieve or recover binaural hearing advantages in speech perception and localization [18-23]. However, research by Peters et al. [24] and Galvin et al. [25-27] has reported more modest benefits for localization, if any.

Localization should be carefully evaluated, as it is a binaural skill that is important in many ways. Localization is important for survival issues, such as identifying the source of a horn in order to avoid an oncoming vehicle; for safety issues, such as identifying where an alarm call comes from, and for everyday communication issues, such as identifying a sound source in multitalker babble. This skill also has an impact on education. Localization is dependent on both interaural time differences and interaural level differences. When a sound is displaced from the centre $\left(0^{\circ}\right.$ azimuth), deviations in both cues arise. Studies have shown that bilateral implantation assists in restoring mainly interaural level difference cues [28$33]$. Therefore, it should, to some degree, restore binaural localization cues in adults $[2,9,31$, $32,34]$ and perhaps allow for the development of such cues in children who receive bilateral CIs $[18,21,23,33-35]$.

This paper aimed to assess the development of lateralization skills in children who received MED-EL CIs bilaterally in sequential operations. Secondly, localization abilities after a period of 5 years of bilateral implant use were measured.

\section{Methods}

Subjects

Nine children who received bilateral MED-EL COMBI 40+ CIs sequentially participated in this study. The average age at first implantation was 4.11 years (range 1.99-6.93), and the average age at second implantation was 5.51 years (range 3.70-7.39). The average time period between implantations was 1.4 years 
Kühn et al.: The Development of Lateralization Abilities in Children with Bilateral Cochlear Implants

Table 1. Subject demographics showing age at first and second implantation, the duration between cochlear implantations, the age at each test interval and the bilateral device experience at each test interval (duration)

\begin{tabular}{|c|c|c|c|c|c|c|c|c|c|}
\hline \multirow{2}{*}{$\begin{array}{l}\text { Subject } \\
\text { ID }\end{array}$} & \multirow{2}{*}{$\begin{array}{l}\text { Age at } \\
\text { left CI }\end{array}$} & \multirow{2}{*}{$\begin{array}{l}\text { Age at } \\
\text { right CI }\end{array}$} & \multirow{2}{*}{$\begin{array}{l}\text { Duration } \\
\text { between CIs }\end{array}$} & \multicolumn{2}{|c|}{ Interval I } & \multicolumn{2}{|c|}{ Interval II } & \multicolumn{2}{|c|}{ Interval III } \\
\hline & & & & age & duration & age & duration & age & duration \\
\hline S1 & 5.6 & 7.3 & 1.7 & 7.8 & 0.5 & 8.4 & 1.1 & 12.1 & 4.8 \\
\hline S2 & 3.8 & 2.4 & 1.4 & & & 4.9 & 1.1 & 8.5 & 4.7 \\
\hline S3 & 3.0 & 3.7 & 0.7 & 4.7 & 1.0 & 5.4 & 1.7 & 9.1 & 5.4 \\
\hline S4 & 6.9 & 7.4 & 0.5 & 7.7 & 0.3 & 8.2 & 0.9 & 11.9 & 4.6 \\
\hline S5 & 5.0 & 4.1 & 0.9 & 6.9 & 1.9 & 7.8 & 2.8 & 11.5 & 6.5 \\
\hline S6 & 4.7 & 3.7 & 1.0 & 5.5 & 0.8 & 6.1 & 1.5 & 9.8 & 5.1 \\
\hline S7 & 2.0 & 3.9 & 1.9 & 5.3 & 1.4 & & & 9.9 & 6.0 \\
\hline S8 & 3.3 & 7.1 & 3.7 & 7.8 & 0.8 & 8.8 & 1.8 & 12.5 & 5.5 \\
\hline S9 & 6.0 & 6.8 & 0.8 & 7.2 & 0.4 & 8.1 & 1.4 & 11.8 & 5.1 \\
\hline
\end{tabular}

All values represent years. The age at implantation shown in bold indicates which ear was implanted first.

(range 0.70-3.74). Table 1 shows individual demographic data for each child. All but 2 children were congenitally deaf. One child was postlingually hearing impaired as a result of meningitis (S6), and 1 child was deafened due to maternal rubella (S4). The etiologies of deafness in the remaining children are unknown. The children participating in this study were 9 of the first 15 children with bilateral implants to begin rehabilitation at the Cochlea-Implantat-Centrum Süd (Würzburg, Germany) from 1999 to 2000. For inclusion in this study, a parent or guardian gave informed consent for the participation of each child, the inclusion of their data in this study and their commitment to continued participation for up to 5 years after implantation.

\section{Test Intervals}

The children were assessed at 3 test intervals after the second cochlear implantation. The timing of these intervals varied, as did the participation of each child in the tests, as they were dependent on the child's ability to perform the task, the complexity of the task and the child's attention span. Test interval I occurred on average 0.89 years after bilateral implantation (range 0.3-2.0), test interval II 1.6 years after bilateral implantation (range 0.86-2.81) and test interval III 5.3 years (range 4.6-6.5) after bilateral implantation (table 1).

\section{Tests}

Children were familiarized with the test conditions using 5 play sessions. The play sessions involved 3 therapists. The child sat blindfolded with the therapists positioned in a semicircle at $0^{\circ}, 90^{\circ}$ and $-90^{\circ}$ azimuth $1 \mathrm{~m}$ away. The child was presented with a sound from a toy clicker. The sound was presented 4 times at each position and in a random order, and the child was instructed to identify which therapist made the sound. Actual testing lasted $15 \mathrm{~min}$ and was performed in an anechoic chamber measuring $6.9 \times 6.9 \times 2.9 \mathrm{~m}$.

At the first 2 test intervals, the children were assessed using a 3-loudspeaker setup. The loudspeakers were placed in front of the child $\left(0^{\circ}\right.$ azimuth), at $-90^{\circ}$ (i.e. to the left of the child) and at $90^{\circ}$ (i.e. to the right of the child), at a distance of $1.8 \mathrm{~m}$ from the child. The speakers were placed in the horizontal plane, at ear level. The stimulus was speech-shaped noise (CCITT noise (Comité Consultatif International Télégraphique et Téléphonique), as standardized in CCITT recommendation 227 [36]), $500 \mathrm{~ms}$ in duration, with a rise/fall time less than $1 \mathrm{~ms}$, presented at a level of $80 \mathrm{~dB}$ SPL. The children were assessed in the bilateral condition, as well as in the unilateral condition using the first CI. At test interval III, the children were assessed using 2 different loudspeaker configurations. The first was as for test intervals I and II, and only the bilateral listening condition was assessed in this setup. In the second loudspeaker condition, localization abilities were also assessed using a 9-loudspeaker setup in the frontal horizontal plane between $-90^{\circ}$ and $90^{\circ}$ azimuth, with speakers spaced $22.5^{\circ}$ apart. To be comparable with data collected from adult bilateral users of the same systems [9], the Würzburg loudspeaker array was extended from 7 to 9 loudspeakers. The stimulus was the same as used in the 3-loudspeaker setup, and testing was again conducted under the bilateral listening condition only. 
In all setups, 5 stimuli per loudspeaker were presented (15 stimuli in the 3-loudspeaker setup and 45 stimuli in the 9-loudspeaker setup), and the children were required to point to the speaker they thought the sound had come from. No feedback as to correct or incorrect responses was given.

\section{Analyses}

Two different performance measures were calculated from the raw lateralization data according to the method described by Nopp et al. [9], namely the mean absolute lateralization error (d) and the lateralization bias (b). In addition, the percentage of correctly identified directions (sc) was calculated. For a more detailed analysis of the unilateral listening conditions, the lateralization bias towards the side measured unilaterally $\left(b_{u}\right)$ was calculated by sign inversion of $b$ if the left CI was implanted first.

SigmaStat software was used for the statistical analyses. Lateralization measures sc, $d$ and b for the 3 time intervals were analyzed using one-way repeated-measures analysis of variance. Post hoc analysis was performed applying the Holm-Sidak method.

Unilateral performance between intervals was evaluated using a paired t test after the normality of the distribution was confirmed using Kolmogorov-Smirnov testing.

A p value of $<0.05$ was considered statistically significant.

Chance error was calculated via Monte Carlo simulation. Localization responses were randomized and the localization measures calculated using those data.

Spearman rank order correlations were calculated between (1) age at first implantation, (2) age at second implantation and (3) duration between the first and second implantation versus the lateralization measures $d, b, b_{u}$ and sc, with first implant only and bilateral implants at all test intervals. In addition, correlation analyses between the duration of bilateral implant use at each interval and the lateralization measures b, $d$ and sc were performed.

\section{Results}

\section{Lateralization Responses}

Lateralization responses averaged across subjects within measurement intervals and listening conditions are displayed in figure 1. Performance with both CIs measured in the 3-loudspeaker setup shows a response pattern that evolved over time from poor lateralization at interval I to nearly perfect lateralization at interval III. In addition, the results indicate that, on average, from interval I to interval II, responses with a single CI change from being uniformly scattered across all directions, indicating poor lateralization abilities, to showing a bias towards the side contralateral to where the $\mathrm{CI}$ is switched on. Although figure 1 shows group data, it is important to note that, in accordance with the average data, subjects S3 and S6, who performed their first unilateral measurement at interval II, showed a consistent contralateral shift of all responses in the unilateral listening condition.

\section{Lateralization Measures}

Lateralization measures $\mathrm{sc}, \mathrm{d}$ and $\mathrm{b}$ derived from bilateral raw lateralization data for the 3 time intervals are shown in table 2. A one-way repeated-measures analysis of variance on this subset of data shows no dependence of $b$ on the measurement intervals $(p=0.89)$. With bilateral CIs, the average $b$ amounts to only $3^{\circ}, 2.3^{\circ}$ and $4.7^{\circ}$ at the 3 test intervals. On the other hand, there are highly significant effects of the test interval on $\mathrm{d}(\mathrm{p}<0.001)$ and $\mathrm{sc}(\mathrm{p}<0.001)$. Post hoc analysis showed that $d$ decreases significantly from 45 to $23.3^{\circ}$ between intervals I and II ( $p=0.002)$, and further down to $4.7^{\circ}$ between intervals II and III ( $\left.p=0.03\right)$. Accordingly, sc increases significantly from 58.3 to $76.7 \%$ between intervals I and II ( $p=0.005)$, and finally to $94.8 \%$ between intervals II and III ( $p=0.024)$.

Unilateral performance (table 3$)$, as assessed using $d, b$ and sc $(n=5)$, with the first CI only did not improve significantly between intervals I and II (paired t tests: $p=0.38$ for $b$, $p=0.41$ for $d$, and $p=0.40$ for $s c$ ). The only significant effect of test interval obtained was an 


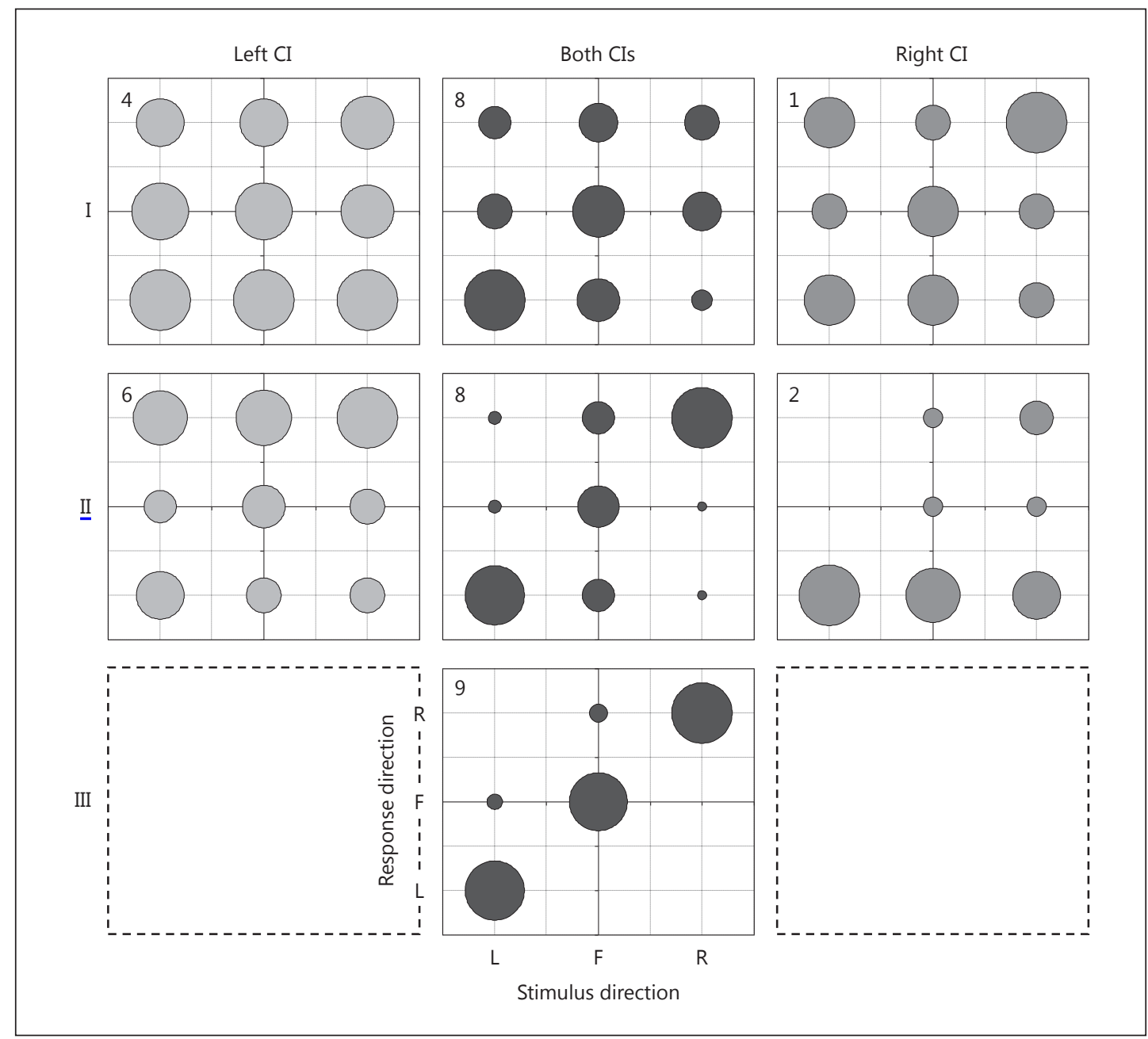

Fig. 1. Lateralization responses averaged across subjects in the 3-loudspeaker setup. Numbers in each plot indicate the number of children tested in the respective conditions. Subject S2 did not perform unilateral tests at all and no bilateral measurements at test interval III. No unilateral measurements were performed for subjects S3, S6 and S8 at test interval I. Although subject 7 was tested with bilateral implants at interval II, his data had to be rejected due to inconsistent recordings. The $\mathrm{x}$-axis depicts the stimulus direction; the $\mathrm{y}$-axis refers to the response direction. The circles correspond to the relative number of responses. I = Interval I; II = interval II; III = interval III; L = left; F = front; R = right.

increase in $b_{u}(p=0.048)$. Lateralization responses were shifted on average by $10.8^{\circ}$ towards the side of the first CI at interval I and by $33^{\circ}$ towards the contralateral side at interval II.

At intervals I and II, both $\mathrm{d}$ and sc demonstrate better performance in the bilateral compared to the unilateral condition. d decreased from an average of $75.6^{\circ}$ (first CI only; table 3 ) to $45^{\circ}$ (both CIs; table 2 ) at interval I, although not significantly ( $\mathrm{p}=0.14$ ), and highly significantly from $70.5^{\circ}$ (first CI only) to $23.3^{\circ}$ (both CIs) at interval II ( $p<0.001$ ). With bilateral CIs, sc increased but not significantly from 37.6 to $58.3 \%$ at interval I $(p=0.160)$, and highly significantly from 43.3 to $76.7 \%$ at interval II ( $\mathrm{p}<0.001)$.

For the 9-loudspeaker setup, individual localization responses for all 9 children obtained at interval III are displayed in figure 2. Individual localization errors and biases are given in table 4 . The average $\mathrm{d}$ amounts to $15.2^{\circ}\left(\operatorname{SD~} 4.26^{\circ}\right)$, and $\mathrm{b}$ is on average $-1.0^{\circ}$ (SD $3.0^{\circ}$ ). 
Table 2. Individual lateralization scores, errors and biases obtained in the 3-loudspeaker setup with bilateral CIs at test intervals I, II and III

\begin{tabular}{|c|c|c|c|c|c|c|c|c|c|c|c|c|}
\hline \multirow[t]{2}{*}{ Measure } & \multirow[t]{2}{*}{ Interval } & \multicolumn{9}{|c|}{ Subject ID } & \multirow[t]{2}{*}{ Mean } & \multirow[t]{2}{*}{ SD } \\
\hline & & S1 & $\mathrm{S} 2$ & S3 & S4 & S5 & S6 & S7 & S8 & S9 & & \\
\hline \multirow[t]{3}{*}{ sc, $\%$} & I & 33 & NA & 60 & 80 & 53 & 33 & 100 & 67 & 40 & 58.3 & 23.70 \\
\hline & II & 67 & 80 & 67 & 87 & 87 & 67 & NA & 80 & 80 & 76.9 & 8.68 \\
\hline & III & 93 & 100 & 93 & 100 & 87 & 93 & 100 & 87 & 100 & 94.8 & 5.47 \\
\hline \multirow[t]{3}{*}{$d,{ }^{\circ}$} & I & 72 & NA & 48 & 18 & 54 & 66 & 0 & 42 & 60 & 45.0 & 24.63 \\
\hline & II & 36 & 18 & 30 & 12 & 12 & 30 & NA & 30 & 18 & 23.3 & 9.32 \\
\hline & III & 6 & 0 & 6 & 0 & 12 & 6 & 0 & 12 & 0 & 4.7 & 5.00 \\
\hline \multirow{3}{*}{$\mathrm{b},{ }^{\circ}$} & I & 0 & NA & 0 & -18 & 6 & 6 & 0 & 30 & 0 & 3.0 & 13.22 \\
\hline & II & -36 & 6 & -18 & 0 & 12 & 6 & NA & 30 & 18 & 2.3 & 20.77 \\
\hline & III & 6 & 0 & 6 & 0 & 12 & 6 & 0 & 12 & 0 & 4.7 & 5.00 \\
\hline
\end{tabular}

NA = No tests were performed in the specified condition.

Table 3. Individual lateralization scores, errors and biases obtained in the 3-loudspeaker setup with the first CI only, at intervals I and II

\begin{tabular}{|c|c|c|c|c|c|c|c|c|c|c|c|c|}
\hline \multirow[t]{2}{*}{ Measure } & \multirow[t]{2}{*}{ Interval } & \multicolumn{9}{|c|}{ Subject ID } & \multirow[t]{2}{*}{ Mean } & \multirow[t]{2}{*}{ SD } \\
\hline & & $\mathrm{S} 1$ & $\mathrm{~S} 2$ & S3 & S4 & S5 & S6 & S7 & S8 & S9 & & \\
\hline \multirow[t]{2}{*}{ sc, $\%$} & I & 20 & NA & NA & 47 & 47 & NA & 27 & NA & 47 & 37.6 & 13.10 \\
\hline & II & 40 & NA & 33 & 33 & 60 & 33 & 47 & 60 & 40 & 43.3 & 11.41 \\
\hline \multirow[t]{2}{*}{$d,{ }^{\circ}$} & I & 84 & NA & NA & 66 & 66 & NA & 102 & NA & 60 & 75.6 & 17.29 \\
\hline & II & 66 & NA & 90 & 72 & 42 & 90 & 60 & 60 & 84 & 70.5 & 16.89 \\
\hline \multirow[t]{2}{*}{$\mathrm{b},{ }^{\circ}$} & I & 0 & NA & NA & -6 & 6 & NA & -30 & NA & -12 & -8.4 & 13.81 \\
\hline & II & 6 & NA & 90 & 0 & -30 & -90 & 24 & -24 & 48 & 3.0 & 54.14 \\
\hline \multirow[t]{2}{*}{$\mathrm{b}_{\mathrm{u}}, \circ$} & I & 0 & NA & NA & 6 & 6 & NA & 30 & NA & 12 & 10.8 & 11.54 \\
\hline & II & -6 & NA & -90 & 0 & -30 & -90 & -24 & 24 & -48 & -33.0 & 41.20 \\
\hline
\end{tabular}

$\mathrm{NA}=$ No tests performed in the specified condition.

Table 4. Individual localization errors and biases obtained in the 9-loudspeaker setup with bilateral CIs at interval III

\begin{tabular}{|c|c|c|c|c|c|c|c|c|c|c|c|}
\hline \multirow[t]{2}{*}{ Measure } & \multicolumn{9}{|c|}{ Subject ID } & \multirow[t]{2}{*}{ Mean } & \multirow[t]{2}{*}{ SD } \\
\hline & $\mathrm{S} 1$ & $\mathrm{~S} 2$ & S3 & S4 & S5 & S6 & S7 & S8 & S9 & & \\
\hline $\mathrm{d},{ }^{\circ}$ & 22 & 16 & 12 & 15 & 13 & 11.5 & 9.5 & 17 & 21 & 15.2 & 4.26 \\
\hline $\mathrm{b},{ }^{\circ}$ & 1 & 3 & -2 & -4 & 3 & 0.5 & -4.5 & -2 & -4 & -1.0 & 2.97 \\
\hline
\end{tabular}

With bilateral CI use, all children demonstrated the ability to localize sound sources in the frontal horizontal plane, as indicated by the fact that for the 3-loudspeaker setup, both the lateralization error $d$ and the score sc are significantly different from chance levels $\left(80^{\circ}\right.$ for d, 33.3\% for sc) throughout all test intervals (table 5). When tested with the first CI only, a significant difference could be found for sc only at interval II. The lack of significance for d indicates that improvement of lateralization with $1 \mathrm{CI}$ is only slight and inconsistent (table 5). 
Kühn et al.: The Development of Lateralization Abilities in Children with Bilateral Cochlear Implants

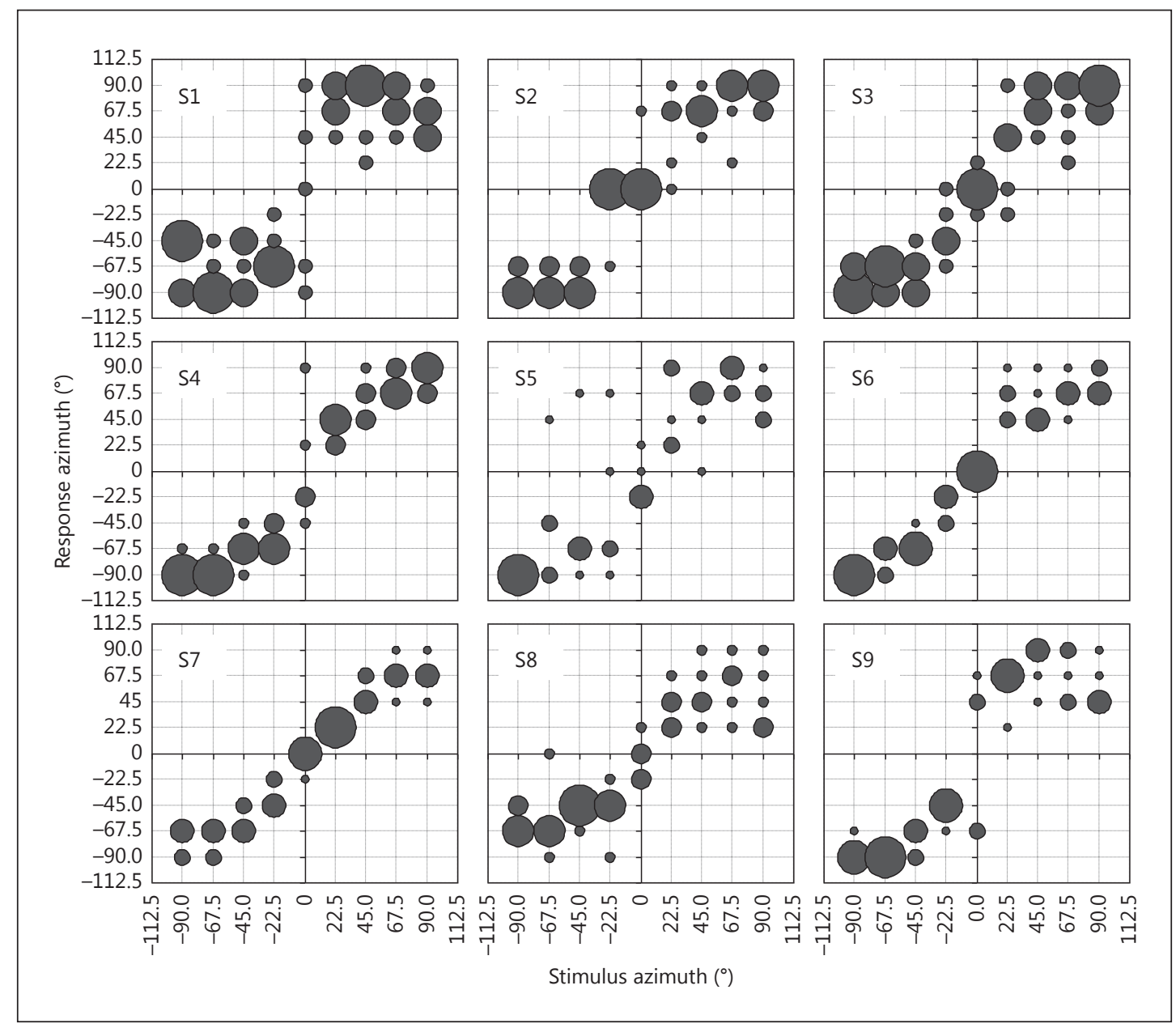

Fig. 2. Individual localization responses in the 9-loudspeaker setup. Circles correspond to the relative number of responses.

Table 5. $\mathrm{p}$ values (paired t tests) indicating differences between lateralization measures and the corresponding chance levels

\begin{tabular}{llllllll}
\hline Interval & \multicolumn{2}{l}{ First CI only } & & & \multicolumn{4}{l}{ Bilateral CIs } \\
\cline { 2 - 3 } \cline { 7 - 8 } & $\mathrm{n}$ & $\mathrm{d}$ & $\mathrm{sc}$ & & $\mathrm{n}$ & $\mathrm{d}$ & $\mathrm{sc}$ \\
\hline I & 5 & 0.60 & 0.53 & & 8 & 0.01 & 0.02 \\
II & 9 & 0.16 & 0.04 & & 8 & $<0.001$ & $<0.001$ \\
III & & & & & 9 & $<0.001$ & $<0.001$ \\
\hline
\end{tabular}

$\mathrm{n}=$ Number of subjects.

\section{Correlation Analyses}

Spearman rank order correlations calculated between the age at first implantation and the duration between first and second implantation versus the lateralization measures $d, b$ and sc, with first implant only and bilateral implants at all test intervals were not significantly correlated. Spearman rank order correlations calculated between age at second implantation and $b_{u}$ showed that at interval II there was a significant correlation $(p=0.03)$. 
Table 6. Correlation between lateralization measures and demographic factors

\begin{tabular}{|c|c|c|c|c|c|c|c|c|c|c|c|}
\hline \multirow[t]{2}{*}{ Interval } & \multirow[t]{2}{*}{ Demographic factor } & \multicolumn{5}{|c|}{ First CI only } & \multicolumn{5}{|c|}{ Bilateral CIs } \\
\hline & & $\mathrm{n}$ & $\mathrm{b}$ & $\mathrm{d}$ & sc & $\mathrm{b}_{\mathrm{u}}$ & $\mathrm{n}$ & $\mathrm{b}$ & $\mathrm{d}$ & sc & $\mathrm{b}_{\mathrm{u}}$ \\
\hline \multirow[t]{3}{*}{ I } & age at 1 st CI & 5 & 0.10 & -0.67 & 0.45 & -0.36 & 8 & -0.40 & 0.36 & -0.34 & -0.40 \\
\hline & age at $2 \mathrm{nd} \mathrm{CI}$ & & 0.30 & -0.36 & 0.11 & -0.67 & & -0.20 & 0.12 & -0.07 & -0.20 \\
\hline & gap between CIs & & -0.20 & 0.82 & 0.78 & 0.21 & & 0.63 & 0.00 & 0.01 & 0.63 \\
\hline \multirow[t]{3}{*}{ II } & age at 1 st CI & 8 & -0.14 & 0.10 & -0.24 & 0.22 & 8 & -0.06 & -0.31 & 0.37 & -0.06 \\
\hline & age at $2 \mathrm{nd} \mathrm{CI}$ & & -0.26 & -0.24 & 0.07 & $0.74^{*}$ & & 0.01 & -0.09 & 0.38 & 0.01 \\
\hline & gap between CIs & & -0.29 & -0.51 & 0.66 & 0.37 & & 0.25 & 0.57 & -0.29 & 0.25 \\
\hline \multirow[t]{3}{*}{ III } & age at 1 st CI & & & & & & 9 & 0.00 & 0.00 & 0.00 & 0.00 \\
\hline & age at $2 \mathrm{nd} \mathrm{CI}$ & & & & & & & 0.09 & 0.09 & -0.09 & 0.09 \\
\hline & gap between CIs & & & & & & & 0.26 & 0.26 & -0.26 & 0.26 \\
\hline
\end{tabular}

$\mathrm{n}=$ Number of subjects. $*$ Significant correlation.

Table 7. Correlation between duration of bilateral implant use and biases, errors and lateralization scores
Fig. 3. Individual lateralization errors obtained with bilateral CIs in the 3-loudspeaker setup, plotted over duration of bilateral implant use.

\begin{tabular}{llllr}
\hline Interval & $\mathrm{n}$ & $\mathrm{b}$ & $\mathrm{d}$ & \multicolumn{1}{c}{$\mathrm{sc}$} \\
\hline I & 8 & 0.47 & -0.14 & 0.12 \\
II & 8 & 0.55 & 0.00 & 0.04 \\
III & 9 & 0.58 & 0.58 & -0.58 \\
\hline
\end{tabular}

$\mathrm{n}=$ Number of subjects.

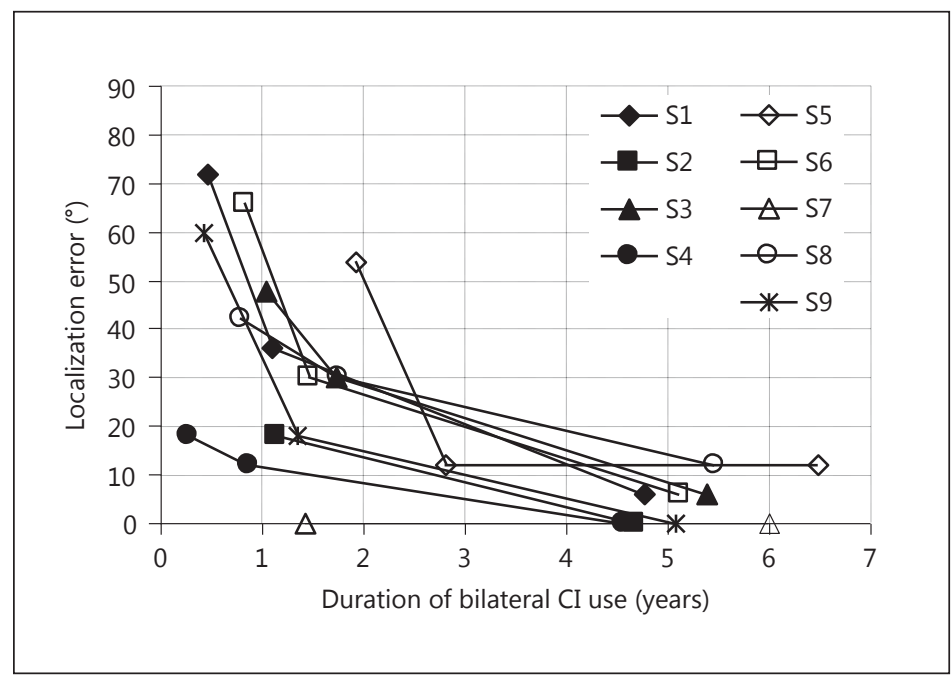

The correlation coefficients between the lateralization measures and demographic factors, i.e. age at first and second implantation and between CIs, for unilateral and bilateral CI use are shown in table 6.

There were no significant correlations between the duration of implant use at each interval and the lateralization measures $b, d$ and sc (table 7). 
Kühn et al.: The Development of Lateralization Abilities in Children with Bilateral Cochlear Implants

\section{Discussion}

Results from this study demonstrate a clear advantage with bilateral CIs in this group of children. With bilateral CI use, all children demonstrated the ability to localize sound sources in the frontal horizontal plane, and lateralization error was significantly lower in children with bilateral CIs than with the first CI. The results further demonstrate substantial learning between all test intervals.

Although the children had used their unilateral CI for on average 1 year at test interval I, they had not developed the ability to localize sounds, i.e. the lateralization error $d$ at interval I with the first CI only is not significantly different from chance error. Once they had received a second CI, their unilateral lateralization abilities did not improve much within the first year of bilateral device use, as indicated by d remaining not significantly different from chance error with unilateral CI use at interval II.

Our results also indicate that children require significant learning before they can make use of their bilateral implants for sound lateralization, illustrated by a significant drop in $\mathrm{d}$ from interval I to interval II to interval III (fig. 3). This is in line with the findings of Buss et al. [37] and Eapen et al. [38] showing that squelch takes years to develop. In the present study, after 1 year of bilateral CI use, most of the children still showed relatively large lateralization errors so that we might state in broad terms that it may take these children up to 3 years to acquire lateralization abilities. In the current study, no correlation was found between $\mathrm{d}$ and age at first or second implant or the interval between implants. This fact might indicate that this broad statement about lateralization acquisition time is relatively robust and can be applied to children implanted between 2 and 6 years of age at first implantation and with a time gap between implants of half a year up to almost 4 years.

Litovsky et al. [34] and others have demonstrated improved localization skills in adults with bilateral hearing provided by CIs, most of whom were postlingually deafened. The 17 adult subjects in that study were implanted simultaneously, which can be seen to be an advantage, as users have immediate access to binaural cues and can start to relearn these binaural skills almost immediately. Interestingly, in that study, the best predictor for improvement in lateralization was duration of bilateral hearing aid use prior to cochlear implantation. This suggests that prior experience with bilateral hearing aids helps users to retain their binaural skills to some extent. A study of 20 sequentially implanted adult CI users showed that all but 2 had substantial improvements in localization ability, improving by more than $30^{\circ}$ on average [9]. The 2 CI users showing no benefit experienced their hearing loss in early childhood. This may indicate either that a longer duration of hearing loss leads to loss of the ability to access binaural cues, even when hearing is stimulated later on in life, or that these 2 subjects never completely developed binaural hearing. Similarly, in the study of Van Deun et al. [21], the children who scored best on localization used hearing aids for 18 or more months before implantation or were first implanted before the age of 2. Steffens et al. [18] suggest that initial binaural auditory experience is related to the high bilateral localization abilities of postmeningitic children reported in their study. This accords with findings showing that users implanted simultaneously have good access to localization cues [27, 34].

It is interesting to note that the average value of $\mathrm{d}$ of our children in the 9-loudspeaker setup $\left(15.2^{\circ}\right.$; table 4$)$ is not significantly different ( $p=0.44, t$ test) from the average $d\left(16.6^{\circ}\right)$ found in the above-mentioned group of adult bilateral CI users, when the 2 adults with hearing losses in early childhood are excluded [9]. This could indicate that bilateral cochlear implantation ultimately allows children with early hearing loss to acquire binaural hearing to a degree that enables them to localize sounds with the same accuracy as postlingually deafened bilaterally implanted adults who acquired binaural hearing initially through acoustic hearing. 
In any case, most postlingually deafened adults have previous experience with binaural cues prior to their hearing loss and appear to quickly relearn these skills after bilateral implantation (cases of very early hearing loss may be an exception). What are the implications, then, for adults deafened early, who might never have acquired these skills, or for children who have had no previous audition and thus no binaural experience to begin with?

In the 2007 study of Beijen et al. [39], 5 children, all with perilingual hearing loss following meningitis, received CIs either simultaneously (4) or sequentially (1, with a 6-month time interval in between). The children in this study could serve as their own controls, as they did not have a more experienced listening ear. These children showed significant benefits of bilateral versus unilateral cochlear implantation on $-90^{\circ}$ and $90^{\circ}$ as well as $-30^{\circ}$ and $30^{\circ}$ setups. They also performed significantly better than a control group of unilaterally implanted children. These children also showed significant benefit as demonstrated on the spatial domain subscale of the SSQ (Speech, Spatial and Qualities of Hearing Scale) quality of life questionnaire. However, it is significant that this group all had some auditory experience before losing their hearing (between 14 and 22 months), which may have impacted on outcomes.

In an early study of localization skills in prelingually hearing-impaired children [34], 3 children performed slightly but not significantly better in the binaural than in the monaural condition. Their scores for identifying source location in the binaural condition were slightly but not significantly above chance. However, the measurements took place 3 months after binaural switch-on, which is probably too soon to see evidence of emerging binaural skills. This was the experience in the current study, where skills took at least 1 year to develop. Further studies by that group $[20,22,40,41]$ show that, despite large variability in performance across individuals, within the first $1-2$ years, about $70 \%$ or more of their samples learned how to identify where a sound comes from. Those studies concur with the evidence from the current study that there is a learning process, in which children learn how to use and process the bilateral information they receive. These results highlight the fact that children are able to take advantage of the input from both CIs without having prior binaural experience $[20,22,41]$. This learning process is also clearly evidenced in the current study, in the development of localization abilities over time and in all cases. This learning process is also highlighted in observations that younger children with shorter times between implantations developed better directional hearing abilities, while those children who had longer times between implantations also developed directional hearing skills after about 1 year of bilateral device experience [16].

Localization skills in the bilateral condition were significantly better in a sample of mostly simultaneously implanted children studied by Beijen et al. [39]. Would a short interval between implantations provide an added advantage for these children? In the current study, there was no correlation between localization skills and the gap between the two cochlear implantations. In this case, the minimum gap was 0.46 years and the maximum was 3.7 years. A review of 2 bilaterally implanted children and the time taken to normalize P1 latency values showed that the child with a very short time between implantations (1 year) had a P1 value that normalized to that of normal-hearing children [42]. However, in a case where the difference between CIs was 8.2 years, the P1 latency did not normalize in the case of the second CI. This hints at cortical mechanisms underlying the sensitive period and suggests that earlier bilateral implantation is better for the development of binaural processing abilities. This may well be the case, though it is not demonstrated in the current study, possibly due to the fact that the largest gap was 3.7 years, which is substantially shorter than the 8.2 years reported in the study by Sharma et al. [42]. The interesting question would be to determine when this critical period for the development of binaural skills ends and when is the best time to implant bilaterally to best make use of this cortical plasticity. The youngest child in the 
current study received their first implant at 23.9 months. There was no correlation between age at implantation and lateralization skills. The lack of correlation between these factors, and also between lateralization skills and the gap between implantations, concurs with data from a previous study on speech listening in noise in children with bilateral CIs [16]. In that study, a linear regression analysis of data from 39 children showed no significant influence of the gap between implantations or age at first CI on speech perception in noise tests. This concurrence of two different bilateral skills suggests that localization abilities and segregation of speech in noise may be interlinked in some manner.

What is the broader importance of receiving bilateral implants and, with them, access to binaural skills such as localization? Currently, most children receive their CIs sequentially; thus, they are bilaterally hearing impaired until they receive their first $\mathrm{CI}$, at which point they could be considered unilaterally hearing impaired. The same could be said for children who receive only one CI. An extensive overview of the difficulties that unilaterally hearing-impaired children experience can be found in the report of Cho Lieu [43]. Tharpe [44] (2008) provides a more recent review, and Borton et al. [45] (2010) report on measures of pediatric quality of life for children in this condition. Profoundly unilaterally hearing-impaired children exhibit educational and behavioral problems and have been recognized to have significantly more communication problems, including delay in sentence development, difficulties in speech development influencing oral abilities and reading and language delays. The impact of unilateral hearing loss on education is clearly confirmed. In one study, $59 \%$ of children with unilateral hearing impairment had a history of academic or behavioral problems at school [46]. In a cohort of 115 children with profound unilateral hearing loss, $22 \%$ had failed a grade and $12 \%$ required additional assistance for learning difficulties [47]. In a seminal study on unilateral profound hearing loss [48], 35\% of 60 children had failed a grade, $13 \%$ needed additional educational assistance and $20 \%$ had behavioral problems identified by teachers. One possible reason for this may be the difficulty these children have in hearing speech in noise. Tharpe's [44] 2008 review found that up to 35\% (average 25.5\%) of children with unilateral hearing loss failed one or more grades, and an even higher number of pupils (up to $60 \%$, on average $31.5 \%$ ) needed resource help for at least 1 year [44]. Moreover, children in this group were found to have significantly poorer abilities than their normal-hearing peers in both lateralization and speech perception (especially at negative signal-to-noise ratios) [44]. Studies have shown that bilateral CIs do assist in improving listening in noise and may nullify this problem, to some degree [16, 40,41]. However, listening in noise also depends on localization skills. Localization abilities allow a child to detect the speaker in the background noise and focus on him or her, and this may further help a child within the educational setting. Thus, making the jump, improvements in localization abilities may improve focus on speakers and may generally improve classroom attention skills, thus moderating or eliminating some factors contributing to educational and behavioral problems experienced by unilaterally hearing-impaired children.

\section{Conclusion}

Results from this study and the literature show that children who have had little or no previous experience with binaural cues are able to access these cues after bilateral cochlear implantation, and that the development of these listening skills takes place over time. To what extent the ability to use binaural cues depends on whether subjects are simultaneously or sequentially implanted, age at implantation, time delay between implantations and therapy provided during the process will have to be investigated in detail in future research. 
Kühn et al.: The Development of Lateralization Abilities in Children with Bilateral Cochlear Implants

\section{Acknowledgments}

The authors would like to thank MED-EL, Innsbruck, Austria, for supporting the assessment of the children with a 9-loudspeaker setup at the third time interval. The authors are very appreciative of the many constructive suggestions of Ilona Anderson, Peter Schleich and Peter Nopp on previous versions of the manuscript. Finally, the authors thank the children for their cheerful and willing participation in this experiment.

\section{References}

- 1 Schön F, Müller J, Helms J: Speech reception thresholds obtained in a symmetrical four-loudspeaker arrangement from bilateral users of MED-EL cochlear implants. Otol Neurotol 2002;23:710-714.

- 2 Schön F, Müller J, Helms J, Nopp P: Sound localization and sensitivity to interaural cues in bilateral users of the Med-El Combi 40/40+ cochlear implant system. Otol Neurotol 2005;26:429-437.

- 3 Müller J, Schön F, Helms J: Speech understanding in quiet and noise in bilateral users of the MED-EL COMBI 40/40+ cochlear implant system. Ear Hear 2002;23:198-206.

4 Tyler R, Dunn C, Witt S, Noble W: Speech perception and localization with adults with bilateral sequential cochlear implants. Ear Hear 2007;28:86S-90S.

- 5 Dunn CC, Tyler RS, Oakley S, Gantz BJ, Noble W: Comparison of speech recognition and localization performance in bilateral and unilateral cochlear implant users matched on duration of deafness and age at implantation. Ear Hear 2008;29:352-359.

6 Mosnier I, Sterkers O, Bebear J-P, Godey B, Robier A, Deguine O, Fraysse B, Bordure P, Mondain M, Bouccara D, Bozorg-Grayeli A, Borel S, Ambert-Dahan E, Ferrary E: Speech performance and sound localization in a complex noisy environment in bilaterally implanted adult patients. Audiol Neurotol 2008;14:106-114.

7 Litovsky RY, Parkinson A, Arcaroli J: Spatial hearing and speech intelligibility in bilateral cochlear implant users. Ear Hear 2009;30:419-431.

- 8 Noble W, Tyler RS, Dunn CC, Bhullar N. Younger- and older-age adults with unilateral and bilateral cochlear implants: speech and spatial hearing self-ratings and performance. Otol Neurotol 2009;30:921-929.

- 9 Nopp P, Schleich P, D’Haese P: Sound localization in bilateral users of MED-EL COMBI 40/40+ cochlear implants. Ear Hear 2004;25:205-214.

-10 Verschuur C, Lutman M, Ramsden R, Greenham P, O’Driscoll M: Auditory localization abilities in bilateral cochlear implant recipients. Otol Neurotol 2005;26:965-971.

11 Grantham D, Ashmead D, Ricketts T, Labadie R, Haynes D: Horizontal-plane localization of noise and speech signals by post-lingually deafened adults fitted with bilateral cochlear implants. Ear Hear 2007;28:524-541.

12 Neuman AC, Haravon A, Sislian N, Waltzman SB: Sound-direction identification with bilateral cochlear implants. Ear Hear 2007;28:73-82.

13 Schleich P, Nopp P, D’Haese P: Head shadow, squelch, and summation effects in bilateral users of the MED-EL COMBI 40/40+ cochlear implant. Ear Hear 2004;25:197-204.

14 Grantham D, Ricketts T, Ashmead D, Labadie R, Haynes D: Localization by post-lingually deafened adults fitted with a single cochlear implant. Laryngoscope 2008;118:145-151.

15 Litovsky RY: Development changes in the precedence effect: estimates of minimum audible angle. J Acoust Soc Am 1997;102:1739-1745.

16 Kühn-Inacker H, Shehata-Dieler W, Müller J, Helms J: Bilateral cochlear implants: a way to optimize auditory perception abilities in deaf children? Int J Pediatr Otorhinolaryngol 2004;68:1257-1266.

17 Bauer PW, Sharma A, Martin K, Dorman M: Central auditory development in children with bilateral cochlear implants. Arch Otolaryngol Head Neck Surg 2006;132:1133-1136.

-18 Steffens T, Lesinski-Schiedat A, Strutz J, Aschendorff A, Klenzner T, Ruhl S, Voss B, Wesarg T, Laszig R, Lenarz T: The benefits of sequential bilateral cochlear implantation for hearing-impaired children. Acta Otolaryngol 2008;128:164-176.

19 Grieco-Calub T, Litovsky R, Werner L: Using the observer-based psychophysical procedure to assess localization acuity in toddlers who use bilateral cochlear implants. Otol Neurotol 2008;29:235-239.

20 Litovsky R, Grieco-Calub T, Godar S: Emergence of sound localization acuity in children who are fitted with bilateral cochlear implants. J Acoust Soc Am 2008;123:3057.

21 Van Deun L, van Wieringen A, Scherf F, Deggouj N, Desloovere C, Offeciers FE, Van de Heyning PH, Dhooge IJ, Wouters J: Earlier intervention leads to better sound localization in children with bilateral cochlear implants. Audiol Neurotol 2009;15:7-17.

22 Godar SP, Litovsky RY: Experience with bilateral cochlear implants improves sound localization acuity in children. Otol Neurotol 2010;31:1287-1292.

23 Grieco-Calub TM, Litovsky RY: Sound localization skills in children who use bilateral cochlear implants and in children with normal acoustic hearing. Ear Hear 2010;31:645-656.

24 Peters B, Litovsky R, Lake J, Parkinson AJ: Sequential bilateral cochlear implantation in children. Intl Congress Series 2004;1273:462-465. 
Kühn et al.: The Development of Lateralization Abilities in Children with Bilateral Cochlear Implants

25 Galvin K, Mok M, Dowell R: Perceptual benefit and functional outcomes for children using sequential bilateral cochlear implants. Ear Hear 2007;28:470-482.

26 Galvin K, Mok M, Dowell R, Briggs R: 12-month post-operative results for older children using sequential bilateral implants. Ear Hear 2007;28:19S-21S.

-27 Galvin KL, Mok M, Dowell RC, Briggs R: Speech detection and localization results and clinical outcomes for children receiving sequential bilateral cochlear implants before four years of age. Int J Audiol 2008;47:636646.

28 Grantham D, Ashmead D, Ricketts T, Haynes D, Labadie R: Interaural time and level difference thresholds for acoustically presented signals in post-lingually deafened adults fitted with bilateral cochlear implants using CIS+ processing. Ear Hear 2008;29:33-44. Seeber B, Fastl H: Localization cues with bilateral cochlear implants. J Acoust Soc Am 2008;123:1030-1042. van Hoesel RJM: Exploring the benefits of bilateral cochlear implants. Audiol Neurotol 2004;9:234-246.

-31 Laback B, Pok S, Baumgartner W, Deutsch Werner, Schmid K: Sensitivity to interaural level and envelope time differences of two bilateral cochlear implant listeners using clinical sound processors. Ear Hear 2004;25: 488-500.

32 Aronoff JM, Yoon YS, Freed DJ, Vermiglio AJ, Pal I, Soli SD: The use of interaural time and level difference cues by bilateral cochlear implant users. J Acoust Soc Am 2010;127:EL87-EL92.

-33 Salloum CA, Valero J, Wong DD, Papsin BC, van Hoesel R, Gordon KA: Lateralization of interimplant timing and level differences in children who use bilateral cochlear implants. Ear Hear 2010;31:441-456.

34 Litovsky RY, Parkinson A, Arcaroli J, Peters R, Lake J, Johnstone P, Yu G: Bilateral cochlear implants in adults and children. Arch Otolaryngol Head Neck Surg 2004;130:648-655.

35 Edelmann K: Richtungshören bei Kindern mit bilateralen Cochlea-Implantaten im Vergleich zu Kindern mit unilateralem Cochlea-Implantat. Dissertation, Universität Würzburg, 2005.

36 Fastl H: A masking noise for speech intelligibility tests; in Proceedings TC Hearing. Acoustical Society of Japan, 1993, pp H93-H70.

-37 Buss E, Pillsbury H, Buchman C, Pillsbury C, Clark M, Haynes D, Labadie R, Amberg S, Roland P, Kruger P, Novak M, Wirth J, Black J, Peters R, Lake J, Wackym P, Firszt J, Wilson B, Lawson D, Schatzer R, D’Haese P, Barco A: Multicenter U.S. bilateral MED-EL cochlear implantation study: speech perception over the first year of use. Ear Hear 2008;29:20-32.

-38 Eapen RJ, Buss E, Adunka MC, Pillsbury HC, Buchman CA: Hearing-in-noise benefits after bilateral simultaneous cochlear implantation continue to improve 4 years after implantation. Otol Neurotol 2009;30:153-159.

-39 Beijen JW, Snik AFM, Mylanus EAM: Sound localization ability of young children with bilateral cochlear implants. Otol Neurotol 2007;28:479-485.

40 Litovsky RY, Johnstone PM, Godar S, Agrawal SS, Parkinson A, Peters R, Latke J: Bilateral cochlear implants in children: localization and acuity measured with minimum audible angle. Ear Hear 2006;27:43-59.

41 Litovsky RY, Johnstone PM, Godar SP: Benefits of bilateral cochlear implants and/or hearing aids in children. Int J Audiol 2006;45(suppl 1):S78-S91.

42 Sharma A, Dorman MF, Kral A: The influence of a sensitive period on central auditory development in children with unilateral and bilateral cochlear implants. Hear Res 2005;203:134-143.

$\$ 43$ Cho Lieu JE: Speech-language and educational consequences of unilateral hearing loss in children. Arch Otolaryngol Head Neck Surg 2004;130:524-530.

44 Tharpe AM: Unilateral and mild bilateral hearing loss in children: past and current perspectives. Trends Amplif 2008;12:7-15.

45 Borton SA, Mauze E, Lieu JE: Quality of life in children with unilateral hearing loss: a pilot study. Am J Audiol 2010;19:61-72.

-46 Brookhouser PE, Worthington DW, Kelly WJ: Unilateral hearing loss in children. Laryngoscope 1991;101: 1264-1272.

47 Bovo R, Martini A, Agnoletto M, Beghi A, Carmignoto D, Milani M, Zangaglia A: Auditory and academic performance of children with unilateral hearing loss. Scand Audiol Suppl 1988;30:71-74.

48 Bess FH, Tharpe AM: Unilateral hearing impairment in children. Pediatrics 1984;72:206-216. 